\title{
Obtenção e Caracterização de Compósitos Utilizando Poliestireno como Matriz e Resíduos de Fibras de Algodão da Indústria Têxtil como Reforço
}

\author{
Cleide Borsoi, Lisete C. Scienza, Ademir J. Zattera \\ Laboratório de Polímeros - PGEPROTEC - CCET - UCS \\ Clarissa C. Angrizani \\ Laboratório de Materiais Poliméricos - PPGEM - UFRGS
}

\begin{abstract}
Resumo: O objetivo deste trabalho é utilizar fibras de algodão como material de reforço em materiais compósitos poliméricos utilizando o poliestireno como matriz e o poli(estireno-co-anidrido maleico) como agente compatibilizante. Os compósitos foram desenvolvidos em uma extrusora dupla-rosca co-rotacional, precedidos de uma pré-mistura em extrusora mono-rosca e moldados por injeção. Os compósitos foram avaliados mediante ensaios mecânicos, térmicos, termo dinâmico-mecânico e de morfologia dos compósitos produzidos. Os ensaios de flexão e tração mostram que a adição de $20 \%$ de fibra de algodão faz com que essas propriedades aumentem, sendo esse efeito intensificado em presença de compatibilizante. Observou-se aumento da resistência ao impacto com adição de carga; porém, os compósitos com compatibilizante apresentaram resultados inferiores. A HDT para os compósitos com $20 \%$ de fibra de algodão foi de aproximadamente $7{ }^{\circ} \mathrm{C}$. Por meio do TGA, observa-se que a adição de fibras de algodão desloca o início da perda de massa para temperaturas próximas a $200{ }^{\circ} \mathrm{C}$. Na análise de DMTA, observa-se que, com a adição da fibra de algodão, ocorre aumento na rigidez e no módulo de armazenamento. As micrografias mostram redução no pull-out das fibras, devido a uma maior adesão fibra/matriz, com a utilização do agente compatibilizante.
\end{abstract}

Palavras-chave: Compósito termoplástico, fibras de algodão, agente compatibilizante.

\section{Obtainment and Characterization of Composites using Polystyrene as Matrix and Fiber Waste from Cotton Textile Industry as Reinforcement}

\begin{abstract}
The aim of this work is to use cotton fibers as reinforcement in polymeric composites materials using polystyrene as matrix and poly(styrene-co-maleic anhydride) coupling agent. The composites were developed by first mixing in a single screw extruder and a corotation parallel twin screw extruder and injection molded. The composites were characterized by analysis mechanical, thermal, dynamic mechanical thermal and morphology. The results from the flexural and tensile strength demonstrate that the addition of $20 \%$ cotton fibers tends to increase in these properties; however there is increase when using a coupling agent. The impact resistance increased with the increase of load; however the results of the composites with coupling agent were lower than those without. The temperature of thermal deflection increased for all composites, but the increase for the composites with $20 \%$ cotton fiber was approximately $7{ }^{\circ} \mathrm{C}$. The results show that the addition of cotton fibers changes the initial temperature of wheight loss for the composites to temperatures close to $200{ }^{\circ} \mathrm{C}$. The DMTA analysis showed increasing in stiffness and the storage modulus with cotton addition. The micrographs showed a reduction in the pull-out fibers, due to a greater adhesion fiber / matrix with the use of compatibilizer.
\end{abstract}

Keywords: Thermoplastic composites, cotton fibers, coupling agent.

\section{Introdução}

O uso de matérias-primas provenientes de fontes renováveis tem sido foco de interesse em muitos trabalhos, devido ao seu grande potencial na substituição de materiais tradicionais. O uso dessas matérias-primas pode ser visto como uma prática econômica; porém, o mais importante é a tendência de reduzir a utilização de produtos de difícil decomposição ${ }^{[1,2]}$. O uso de fibras naturais, como reforço em materiais compósitos, apresenta um grande potencial para melhorar o desempenho de polímeros em aplicações tecnológicas, além de apresentar baixo custo, abundância e biodegradabilidade ${ }^{[3-5]}$. Esses materiais combinam boas propriedades mecânicas com uma baixa massa específica e boa estabilidade dimensional ${ }^{[6]}$. Além disso, essas fibras geram menor impacto ambiental na sua produção ${ }^{[7]}$.
Compósitos que utilizam fibras naturais, como carga de reforço, e polímeros biodegradáveis, como matriz, são considerados materiais ambientalmente amigáveis ${ }^{[8]}$. Estudos demonstram que as fibras de origem vegetal têm um impacto muito pequeno sobre o meio ambiente, quando comparado com o das fibras de vidro ${ }^{[6]}$. Fibras como sisal, coco, juta, rami, folha de abacaxi, algodão, curauá e linho, entre outras, estão sendo estudadas como carga de reforço em compósitos, devido ao seu grande potencial ${ }^{[9]}$. As fibras de algodão têm propriedades físicas muito promissoras em compósitos matriz/fibra de algodão (e.g. processados por extrusão); porém, a maior parte dos estudos sobre esses materiais tem se centrado em compósitos matriz/tecido de algodão ${ }^{[10]}$.

Autor para correspondência: Ademir J. Zattera, Laboratório de Polímeros, PGEPROTEC, CCET, Universidade de Caxias do Sul, 
A incorporação de fibras vegetais em termoplásticos vem sendo estudada devido a fatores tais como: aumento do módulo de elasticidade e resistência mecânica, além de reduzir o peso do produto final ${ }^{[11]}$.

As fibras naturais celulósicas são hidrofílicas e geralmente incompatíveis com matrizes poliméricas hidrofóbicas ${ }^{[12]}$; isso requer um tratamento das fibras ou a utilização de agentes compatibilizantes, que promovam ligações químicas entre a matriz e a carga de reforço, ou que alterem a tensão superficial da carga de reforço, para permitir um molhamento eficiente da matriz pela fibra, melhorando a adesão entre a carga de reforço e a matriz ${ }^{[4]}$. A interação da fibra no compósito não é apenas uma função da resistência à tração da fibra, do seu comprimento e da fração volumétrica desta no compósito, mas também depende da natureza química e da ligação física entre a fibra e a matriz polimérica. As interações fibra/matriz desempenham um papel fundamental na transferência de tensão da matriz para a fibra. A ligação entre a fibra e a matriz é criada durante a fase de produção dos materiais compósitos ${ }^{[13,14]}$.

A presença de água livre e grupos $\mathrm{OH}$, especialmente nas regiões amorfas, prejudica a capacidade de aderência da fibra na matriz. A alta absorção de água e umidade na fibra de celulose provoca inchaço e efeito de plasticidade, o que resulta em instabilidade dimensional e baixas propriedades mecânicas ${ }^{[15]}$. A incompatibilidade de componentes é responsável por uma baixa aderência na interface fibra/matriz e baixa dispersão de fibras, o que causa uma diminuição das propriedades mecânicas desses materiais ${ }^{[14]}$; assim, um agente de acoplamento (agente compatibilizante) é necessário. O agente compatibilizante mais comumente usado é o de poliolefinas graftizadas com anidrido maleico, utilizado na mistura de polímeros e fibras para a obtenção do compósito ${ }^{[7]}$.

O objetivo deste trabalho consiste em avaliar a viabilidade técnica da utilização de resíduos da indústria têxtil, reaproveitandoos em materiais compósitos poliméricos, como materiais passíveis de reciclagem com alto valor agregado e baixo custo. Para isso, foi avaliada a influência de diferentes teores de carga de reforço com ou sem adição de agente compatibilizante nas propriedades mecânicas, térmicas, termo dinâmico-mecânico, e morfológicas dos compósitos.

\section{Experimental}

\section{Materiais}

O algodão utilizado é um fio com título $8 / 2 \mathrm{Ne}$, o qual é resíduo de processo proveniente da fabricação de tecidos em máquinas de tecelagem. De acordo com Pita ${ }^{[15]}$, o título de um fio expressa a relação entre a massa do fio e seu comprimento. O sistema utilizado para fios de algodão é o sistema indireto, cujo título é o comprimento por unidade de massa; com isso, quanto mais fino for o fio maior será o comprimento por unidade de peso. O sistema $\mathrm{Ne}$ é um sistema inglês de medida. O comprimento médio das fibras utilizadas foi de $50 \mathrm{~mm}$, não sendo realizado nenhum tratamento na fibra de algodão. Como matriz foi utilizado o poliestireno virgem com índice de fluidez - MFI $\left(200{ }^{\circ} \mathrm{C}, 5 \mathrm{~kg}\right)$ igual a $20 \mathrm{~g} / 10 \mathrm{~min}$, fornecido pela empresa Innova. $\mathrm{O}$ agente compatibilizante utilizado foi o copolímero comercial de poli(estireno-co-anidrido maleico), com massa molar ponderal - Mw igual a 5612 g. $\mathrm{mol}^{-1}$, fornecido pela empresa Sartomer Company, na forma de flakes com nome comercial de SMA 2000. A quantidade em massa de anidrido maleico, de acordo com o fornecedor, é de aproximadamente $30 \%$.

\section{Processamento}

\section{Extrusão}

Antes do processo de extrusão, as fibras de algodão foram submetidas à secagem em estufa por 12 horas a $70{ }^{\circ} \mathrm{C}$. O agente compatibilizante foi triturado e misturado manualmente à fibra de algodão e ao PS cristal. Foi realizada uma pré-mistura do PS e da fibra de algodão em extrusora mono-rosca, modelo ES 35FR. As temperaturas nas diferentes zonas de aquecimento variam conforme o seguinte perfil: 140,160 e $180{ }^{\circ} \mathrm{C}$, com velocidade de rotação da rosca de 42,88 rpm. O compósito foi triturado no moinho de facas e seco em estufa por 12 horas a $70{ }^{\circ} \mathrm{C}$. Após, o material foi extrusado em extrusora dupla-rosca, modelo COR 20-32-LAB, do fabricante MH Equipamentos, que possui oito zonas de aquecimento, com o seguinte pefil: $115,150,185,185,180,175,175$ e $170{ }^{\circ} \mathrm{C}$, e a rotação da rosca foi de $200 \mathrm{rpm}$.

\section{Injeção}

Os corpos de prova foram obtidos em uma injetora, modelo LHS 150-80 fabricante Himaco Hidráulicos e Máquinas Ltda, que possui três diferentes zonas de aquecimento, que variam conforme o seguinte perfil: 150,165 e $180^{\circ} \mathrm{C}$, com o molde à temperatura ambiente e rotação da rosca de $100 \mathrm{rpm}$.

\section{Identificação do compósito}

$\mathrm{Na}$ Tabela 1 estão relacionadas as formulações e a identificação das amostras; a letra P corresponde ao polímero utilizado poliestireno; a letra A corresponde à fibra utilizada - algodão; os dois primeiros números, a quantidade em massa de fibra utilizada, e o último dígito, a quantidade de agente compatibilizante adicionada.

Poletto ${ }^{[16]}$ estudou a obtenção de compósitos utilizando poliestireno reciclado com pó de madeira, como carga de reforço. Neste estudo diferentes teores de agente compatibilizantes foram avaliados (1, 2 e 4\%), sendo que o teor de $2 \%$ em massa de SMA 2000 apresentou os melhores resultados nas análises de flexão, DMTA e MEV. Com isso, no presente estudo foi utilizado 2 phr do SMA 2000 para manter a relação entre a fibra e a matriz.

\section{Ensaios mecânicos}

Tanto os ensaios de flexão como os de tração foram realizados na máquina universal de ensaios EMIC DL 2000. A velocidade utilizada para a realização do ensaio de flexão foi de $1,5 \mathrm{~mm} / \mathrm{min}$, conforme norma ASTM D790. O ensaio de tração foi realizado utilizando uma velocidade de $5 \mathrm{~mm} / \mathrm{min}$, segundo norma ASTM 638.

A análise das propriedades de impacto dos compósitos foram analisadas utilizando o método IZOD, sem entalhe, com pêndulo de $1 \mathrm{~J}$ em equipamento da CEAST, modelo Resil 25, conforme a norma ASTM D 256.

\section{Temperatura de deflexão térmica (HDT)}

As análises de HDT foram realizadas em equipamento CEAST, modelo HDT/6 VICAT. Foi utilizada uma taxa de aquecimento de $120^{\circ} \mathrm{C} / \mathrm{h}$ com uma carga aplicada de $1,82 \mathrm{MPa}$, de acordo com o método A.

Tabela 1. Compósitos com diferentes teores de fibras de algodão.

\begin{tabular}{cccc}
\hline Amostra & $\begin{array}{c}\text { Teor de } \\
\text { PS }\end{array}$ & $\begin{array}{c}\text { Teor de fibra de } \\
\text { algodão }(\%)\end{array}$ & $\begin{array}{c}\text { Teor de SMA 2000 } \\
(\mathbf{p h r})\end{array}$ \\
\hline PA000 & 100 & 0 & 0 \\
PA100 & 90 & 10 & 0 \\
PA102 & 90 & 10 & 2 \\
PA200 & 80 & 20 & 0 \\
PA202 & 80 & 20 & 2 \\
\hline
\end{tabular}




\section{Análise termogravimétrica (TGA)}

As análises de TGA foram realizadas em equipamento Shimadzu TGA-50, em atmosfera de $\mathrm{N}_{2}$ com fluxo de $50 \mathrm{~mL} / \mathrm{min}$. Foi utilizada uma taxa de aquecimento de $10{ }^{\circ} \mathrm{C} / \mathrm{min}$ com faixa de temperatura de $23-600^{\circ} \mathrm{C}$. A massa utilizada foi de aproximadamente $10 \mathrm{mg}$.

\section{Análise termo dinâmico-mecânica (DMTA)}

Para os ensaios de DMTA foram confeccionados corpos de prova com dimensões aproximadas de $50 \times 13 \times 3,5 \mathrm{~mm}$, obtidos a partir dos corpos de prova de flexão moldados por injeção. $\mathrm{O}$ equipamento utilizado foi reômetro oscilatório Anton Paar Physica MCR 101, operando no modo de torção, partindo de 23 até $130^{\circ} \mathrm{C}$, com taxa de aquecimento de $3{ }^{\circ} \mathrm{C} / \mathrm{min}$, na frequência de $1 \mathrm{~Hz}$, com amplitude de deformação de $0,1 \%$.

\section{Microscopia eletrônica de varredura (MEV)}

Para a análise de MEV foi utilizado um microscópio eletrônico de varredura, SHIMADZU, modelo Superscan SS-500, com uma tensão de aceleração de $15 \mathrm{kV}$. Os corpos de prova utilizados foram fraturados no ensaio de tração, sendo as superfícies recobertas com ouro, utilizando-se um metalizador por um tempo de exposição de 3 minutos, antes das análises.

\section{Resultados e Discussão}

\section{Ensaios mecânicos}

\section{Ensaio de flexão}

Na Figura 1, observa-se que a adição de fibra de algodão faz com que a resistência à flexão aumente; uma tendência maior de aumento com a utilização do agente compatibilizante é observada. Sam-Jung Kim et al. ${ }^{[10]}$ constataram que o aumento da porcentagem em massa do agente compatibilizante, PP graftizado com anidrido maleico (PP-g-MAH), aumentou a resistência à flexão do compósito $\mathrm{PP} /$ fibra de algodão e PP/ fibra de madeira, pois ocorre uma maior adesão fibra/matriz PP. Para a amostra com $10 \%$ de fibra com SMA 2000, observa-se uma diminuição da resistência à flexão, devido à possível não uniformidade na distribuição das fibras. Nas imagens de $\mathrm{MEV}$, percebe-se que a distribuição não é homogênea para $10 \%$ de fibra de algodão, devido à baixa concentração de fibras na matriz polimérica (Figura 10). Esse comportamento não ocorre com o aumento do teor de fibra de algodão.

Pode-se observar, na Figura 2, que o módulo de elasticidade aumentou em relação ao PS puro, elevando a rigidez do material. Contudo, os maiores valores encontrados para o módulo de elasticidade correspondem ao percentual de $20 \%$ de fibra de algodão. Acredita-se que o agente compatibilizante utilizado no compósito migrou para o interior da fibra, aumentando seu módulo.

\section{Ensaios de tração}

A Figura 3 apresenta os valores médios de resistência à tração para os corpos de prova ensaiados em cada condição experimental. Pode-se constatar que a adição de algodão ao PS aumentou a resistência à tração, indicando uma melhor transferência de esforços da matriz para o reforço. Valores ainda maiores foram obtidos com a adição do agente compatibilizante. De acordo com Garcia, Garmendia e $\operatorname{Garcia}^{[7]}$, a carência de compatibilidade adequada entre fibra/matriz faz com que a adesão interfacial não seja suficientemente boa, principalmente em relação às propriedades mecânicas. Dessa forma, um agente compatibilizante é requerido para promover uma melhor adesão interfacial, proporcionando um maior desempenho mecânico do compósito.

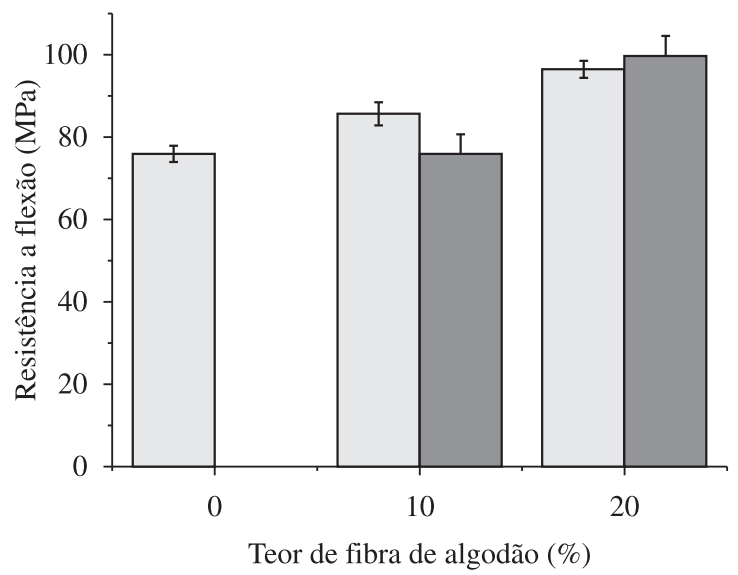

Sem SMA $\square$ Com SMA

Figura 1. Resistência à flexão máxima dos compósitos PS/ fibra de algodão, com e sem SMA 2000.

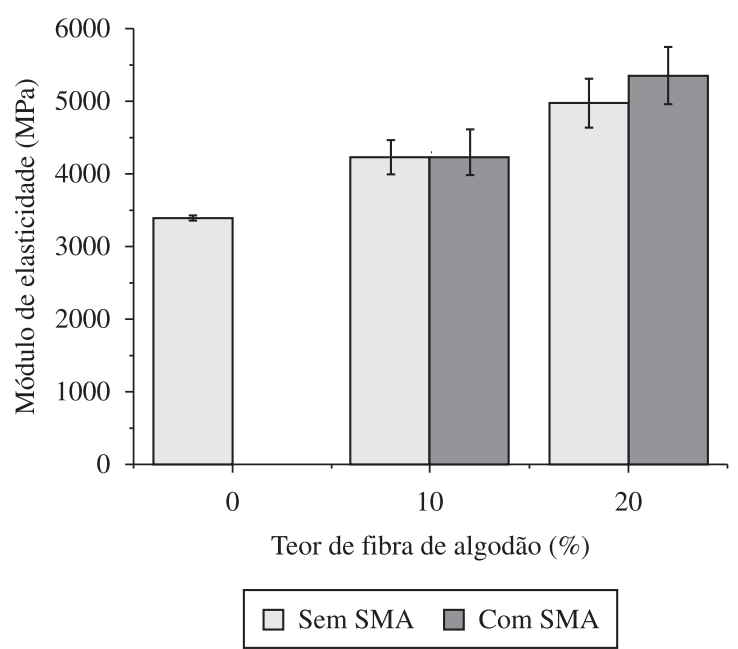

Figura 2. Módulo de elasticidade por flexão dos compósitos PS/ fibra de algodão, com e sem SMA 2000.

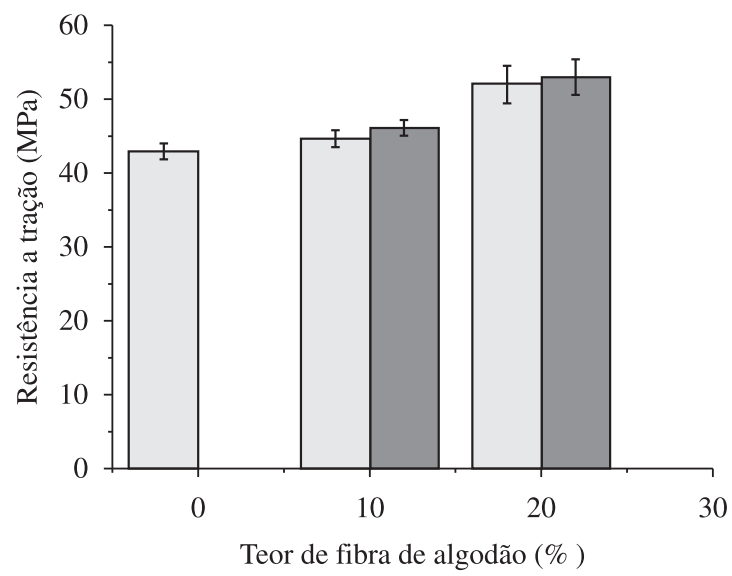

\section{Sem SMA $\square$ Com SMA}

Figura 3. Resistência à tração máxima dos compósitos PS/ fibra de algodão com e sem SMA 2000. 
A resistência à tração depende de alguns fatores, como o tipo de fibra, a razão de aspecto (1/d) e a natureza química da fibra. Em estudo realizado por Mwaikambo e Bisanda ${ }^{[17]}$, a fibra de algodão apresentou um melhor efeito de reforço para o PP, comparado à fibra de madeira.

Na Figura 4, observa-se que o módulo de elasticidade aumentou em relação ao PS, sendo esse efeito mais pronunciado para o percentual de $20 \%$ de fibra de algodão com SMA 2000. Com o incremento do teor de fibras, as tensões passam a ser mais uniformemente distribuídas; com isso, a incorporação de fibras descontínuas na matriz polimérica termoplástica melhora as propriedades de rigidez e resistência dos compósitos obtidos, mediante processo de injeção, eliminando a necessidade de processamento adicional ${ }^{[18]}$.

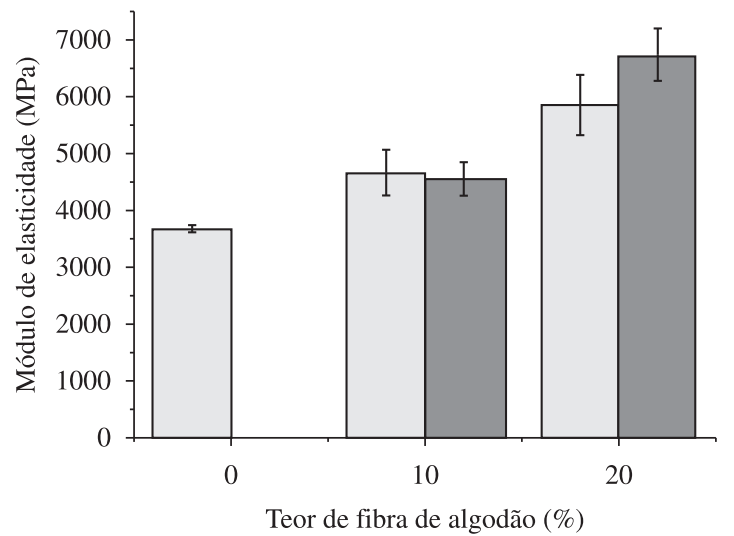

Sem SMA $\square$ Com SMA

Figura 4. Módulo de elasticidade por tração dos compósitos PS/ fibra de algodão com e sem SMA 2000.

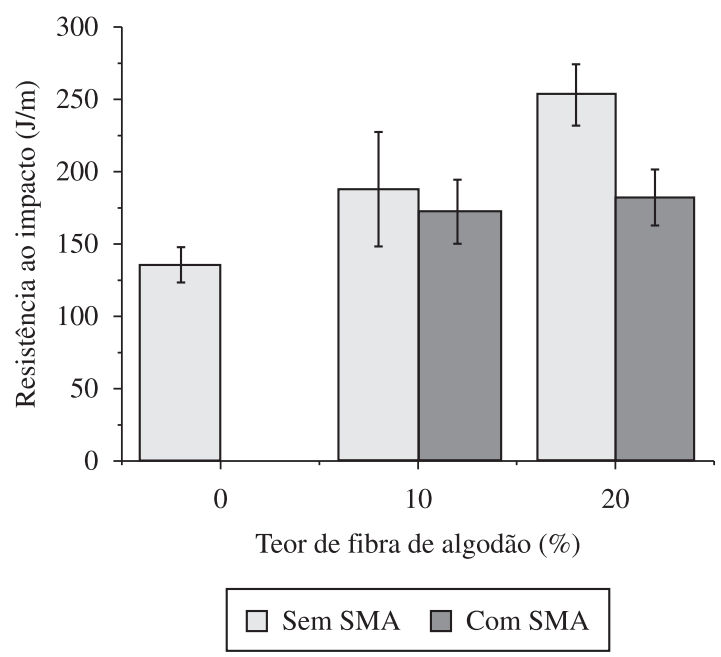

Figura 5. Resistência ao impacto dos compósitos PS/fibra de algodão em função do teor de fibra e da utilização do agente compatibilizante.

Tabela 2. Temperaturas obtidas com ensaio de HDT para compósito PS/ fibra de algodão em comparação à matriz PS.

\begin{tabular}{cc}
\hline Amostra & Temperatura $\left({ }^{\circ} \mathbf{C}\right)$ \\
\hline PA000 & $73,96 \pm 1,26$ \\
PA100 & $76,70 \pm 1,40$ \\
PA102 & $76,90 \pm 0,90$ \\
PA200 & $81,23 \pm 0,76$ \\
PA202 & $80,66 \pm 0,58$ \\
\hline
\end{tabular}

\section{Ensaio de impacto}

A Figura 5 apresenta os resultados da resistência ao impacto dos compósitos preparados com PS e fibra de algodão.

Observa-se que, para as amostras sem agente compatibilizante, a adição das fibras de algodão aumenta a resistência ao impacto dos compósitos, quando comparados com a matriz de PS pela adição de um componente flexível.

A adição do agente compatibilizante reduz a resistência ao impacto, quando comparada com os compósitos desenvolvidos sem agente compatibilizante, mas, quando comparada à matriz PS, a resistência ao impacto é maior. Nesse caso, acredita-se que o agente compatibilizante migrou para o interior da fibra, aumentado seu módulo e reduzindo sua deformação. Sendo assim, obteve-se uma capacidade de absorção de energia menor. A resistência ao impacto para os compósitos com $20 \%$ em massa de fibra de algodão, sem agente compatibilizante, foi de $253,05 \mathrm{~J} . \mathrm{m}^{-1}$ em comparação aos $135,59{\mathrm{~J} . \mathrm{m}^{-1}}^{-}$obtidos para a matriz de PS, o que corresponde a um desempenho $86 \%$ superior ao da matriz.

\section{Análises térmicas}

\section{Análise da temperatura de deflexão térmica}

A Tabela 2 apresenta a temperatura de deflexão térmica para o poliestireno e para os compósitos PS/fibra de algodão.

A presença da fibra de algodão produz um aumento no valor da temperatura de deflexão para todos os compósitos, com uma tendência maior de aumento e menor desvio padrão para os compósitos com $20 \%$ de fibra de algodão. Pelo fato de a fibra ser flexível, ocorre um aumento na resistência ao impacto, e, se a adesão for boa, ocorre um aumento nas propriedades de tração e flexão, por meio da carga de reforço de fibra. Segundo Garcia, Garmendia e $\mathrm{Garcia}^{[7]}$, a adição das fibras naturais em polímeros aumenta a rigidez do material, como pode ser observado pela análise do tan $\delta$ e pelo módulo de elasticidade de tração e flexão, ocasionando um aumento da temperatura de deflexão térmica. Para o compósito com $20 \%$ de fibra de algodão, em relação ao PS, o aumento da temperatura de deflexão térmica foi de aproximadamente $7{ }^{\circ} \mathrm{C}$.

\section{Análise termogravimétrica}

As análises de TGA para os compósitos com diferentes teores de fibra de algodão, com e sem SMA 2000, estão representadas na Figura 6. Para o poliestireno, a degradação tem início em aproximadamente $265{ }^{\circ} \mathrm{C}$, e término em $435{ }^{\circ} \mathrm{C}$. Para o algodão, a primeira perda de massa ocorre antes dos $100{ }^{\circ} \mathrm{C}$ e pode ser atribuída à perda de umidade presente na fibra. A segunda perda de massa inicia próxima a $215{ }^{\circ} \mathrm{C}$ e estende-se até aproximadamente $375^{\circ} \mathrm{C}$, é referente à degradação da hemicelulose e celulose e à lenta degradação da lignina. Os compósitos apresentam um comportamento intermediário entre o PS e a fibra de algodão. A adição de resíduos de algodão em PS acarreta uma redução da estabilidade térmica do material, fazendo com que o processo de degradação térmica inicie em aproximadamente $200{ }^{\circ} \mathrm{C}$. Observase que a perda de massa é mais pronunciada conforme a adição de fibra aumenta e também aumenta com a adição de agente compatibilizante. Uma possível explicação para esse fato é que os compósitos compatibilizados apresentam maior interação interfacial devido às reações entre os grupos ácidos do anidrido maleico e dos grupos hidrofílicos, presentes na superfície da fibra. Esse efeito promove uma maior interação entre os processos de degradação dos dois componentes, ou seja, a degradação de um componente pode acelerar a degradação do outro componente ${ }^{[19]}$.

A Figura 7 mostra a curva da primeira derivada da perda de massa, onde observa-se um primeiro pico em aproximadamente $340^{\circ} \mathrm{C}$ para a fibra de algodão, o que equivale à máxima taxa de decomposição 
do algodão. Um segundo pico é observado em aproximadamente $430{ }^{\circ} \mathrm{C}$ e que equivale à máxima taxa de decomposição do PS. Os compósitos apresentam um comportamento intermediário entre $\mathrm{o}$ algodão e o PS. A máxima taxa de decomposição ocorre em $430{ }^{\circ} \mathrm{C}$.

\section{Análise termo dinâmico-mecânica}

Por meio dos ensaios de DMTA, foram analisados a variação da altura do pico de $\tan \delta$ e o módulo de armazenamento para o PS e para os compósitos PS/fibra de algodão.

Observa-se, na Figura 8, que, com a adição da fibra de algodão, ocorre diminuição da altura do pico, o que pode estar relacionado com a restrição da movimentação dos segmentos de cadeia da matriz, com a incorporação da carga de reforço ${ }^{[20]}$. Uma vez que o valor de $\tan \delta$ indica o grau de amortecimento mecânico, quanto mais flexível for o sistema maior será o grau de amortecimento. Para os compósitos analisados, foi observada uma redução no grau de amortecimento em relação ao PS, como pode ser observado na Figura 8. Com a adição das fibras, diminui-se a fração da matriz, componente de maior ductilidade e, consequentemente, o grau de amortecimento. Com a utilização de agente compatibilizante, a altura do pico é menor em comparação à amostra não compatibilizada; assim, a redução da altura do pico também indica uma boa adesão interfacial ${ }^{[20]}$.

Esses resultados corroboram as análises de módulo de elasticidade por tração e flexão, quando observa-se que a rigidez do material aumentou.

Observa-se, na Figura 9, um aumento do módulo de armazenamento com a incorporação de fibras de algodão. Esse efeito provavelmente ocorre devido ao aumento da rigidez da matriz com a incorporação da carga de reforço, que permitiu um maior grau de transferência de tensões na interface fibra/matriz ${ }^{[18]}$. O módulo de armazenamento (E') é a propriedade mais importante para avaliar a capacidade de carga de um material compósito ${ }^{[20]}$. Para os compósitos com $20 \%$ de fibra e com agente compatibilizante, o módulo de armazenamento é superior ao da amostra não compatibilizada, ao contrário do comportamento verificado para $10 \%$ de fibra. Com a utilização de agente compatibilizante, temse uma melhor adesão na interface fibra/matriz, como pode ser observado nas Figuras 10, 11, 12 e 13, sendo esperado um acréscimo no módulo de armazenamento. Contudo, os compósitos com 10\%

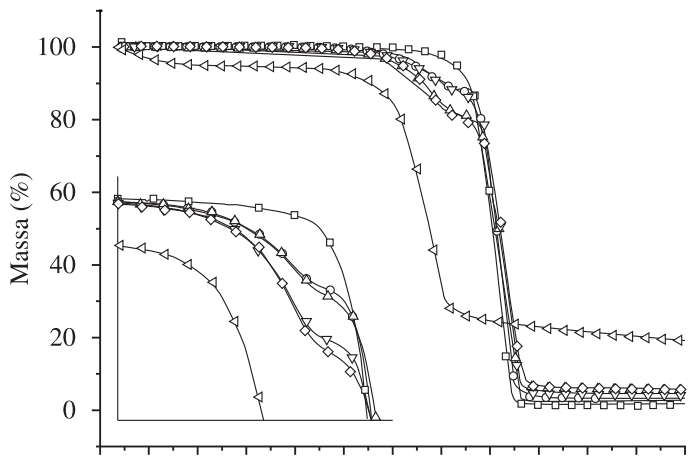

$0 \quad 50100150200250300350400450500550600$

Temperatura $\left({ }^{\circ} \mathrm{C}\right)$

$$
\begin{array}{lll}
\rightarrow \text { PA000 } & - \text { PA100 } & - \text { PA200 } \\
\rightarrow-\text { PA102 } & \prec \text { PA202 } & \downarrow \text { Algodão }
\end{array}
$$

Figura 6. Curva de perda de massa dos compósitos com fibra de algodão em comparação com a curva do PS e do algodão.

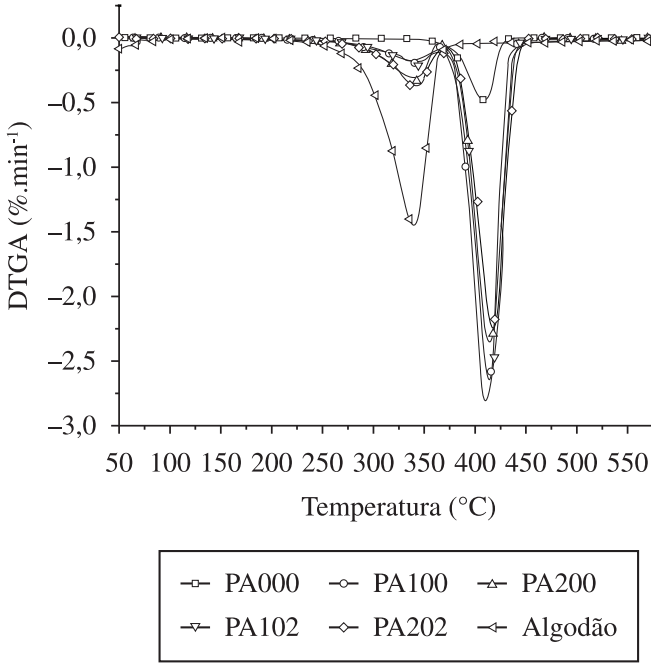

Figura 7. Curva da primeira derivada da perda de massa dos compósitos com resíduo de algodão, em comparação com a curva do PS e do algodão.

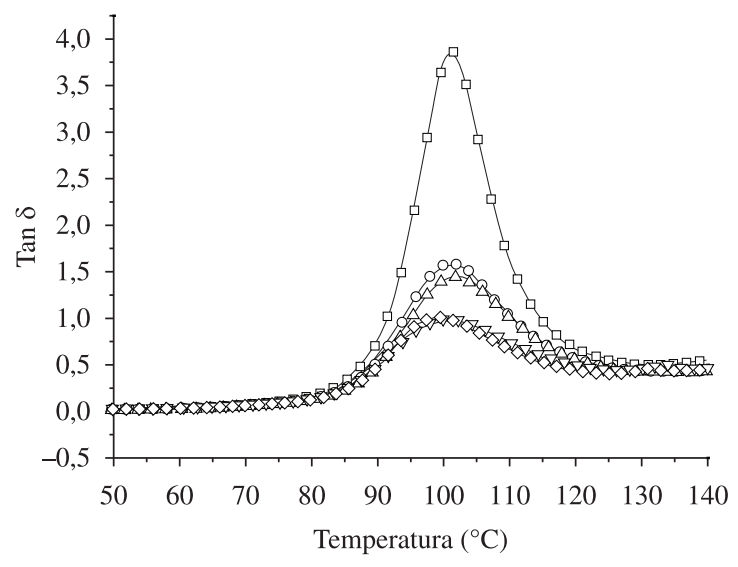

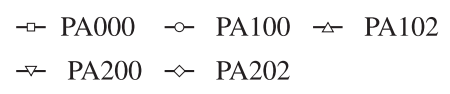

Figura 8. Tan $\delta$ dos compósitos PS/fibra de algodão com e sem agente compatibilizante.

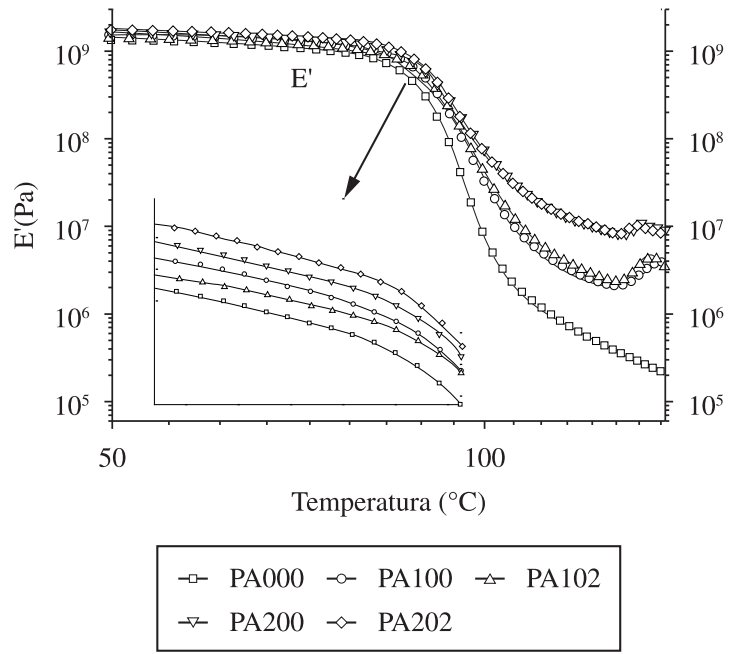

Figura 9. Módulos de armazenamento ( $\left.E^{\prime}\right)$ obtidos mediante análise de DMTA para compósitos, com e sem agente compatibilizante. 
de fibra não apresentaram o efeito esperado, provavelmente devido a uma distribuição não uniforme das fibras no compósito, como observado na Figura 10.

À medida que aumenta a temperatura, o módulo de armazenamento diminui, seguido de um declínio acentuado próximo da região de transição vítrea $(\mathrm{Tg})$. Esse comportamento pode ser atribuído ao aumento da mobilidade molecular das cadeias de polímero acima da $\mathrm{Tg}^{[20]}$.

\section{Microscopia eletrônica de varredura (MEV)}

As Figuras 10 e 11 mostram as imagens obtidas por microscopia eletrônica de varredura dos compósitos PS/fibra de algodão, preparados com e sem agente compatibilizante. Nas microscopias sem o uso de agente compatibilizante, observa-se a presença de vazios deixados pelas fibras arrancadas da matriz no momento da fratura, os quais diminuíram com o uso de SMA 2000. Isso demonstra uma melhor adesão da fibra à matriz, já que a fibra foi rompida mais próxima à superfície da matriz.

Para a amostra com $10 \%$ de fibra e com SMA 2000, observa-se uma diminuição da resistência à flexão, devido à não uniformidade na distribuição das fibras, como pode ser observado pela microscopia (Figura 10). Os compósitos desenvolvidos com baixos teores de fibra não apresentam um aumento significativo na resistência à tração em relação à matriz de PS, ocasionando assim um carregamento ineficiente, como pode ser observado no ensaio de tração (Figura 3) e na distribuição não homogênea das fibras, pois se constatam muitos espaços vazios, sem fibras (Figura 10). A adição de $20 \%$ de fibra de algodão faz com que a distribuição da carga de reforço, na matriz, seja homogênea, como mostra a Figura 11. Isso possibilita um aumento à resistência e à tração e flexão, como foi verificado anteriormente.

Conforme Figura 12a, podem ser observados os espaços vazios, devido à diferença de energia superficial entre a fibra e a matriz ${ }^{[21]}$. A utilização de agente compatibilizante eliminou os espaços vazios, conforme as indicações nas Figuras 12 e 13, demonstrando melhor adesão interfacial e boa molhabilidade entre matriz de PS e fibra de algodão. Esses resultados corroboram com as análises mecânicas, cuja adição de agente compatibilizante promoveu melhorias nas propriedades de tração e flexão. Comportamento semelhante foi verificado por Correa et al. ${ }^{[22]}$, os autores verificaram uma melhora nas propriedades mecânicas dos compósitos PP/farinha de madeira,
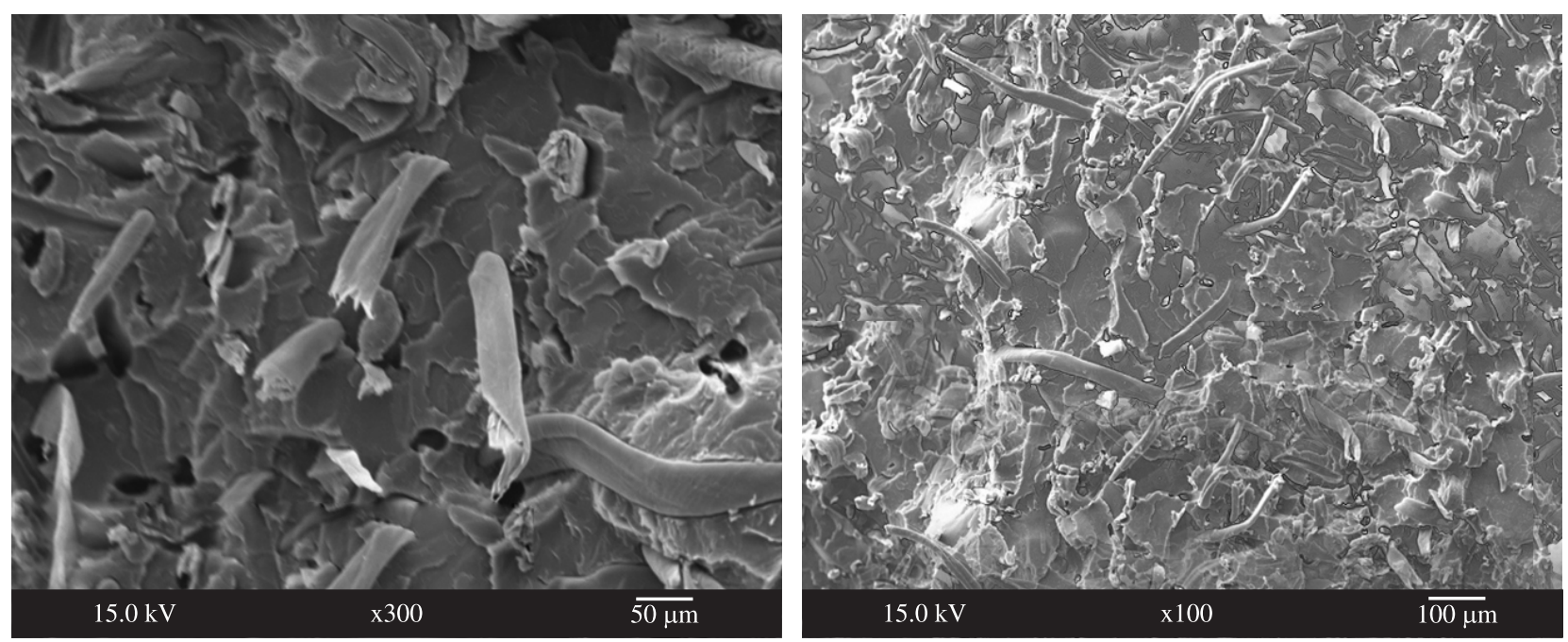

(a)
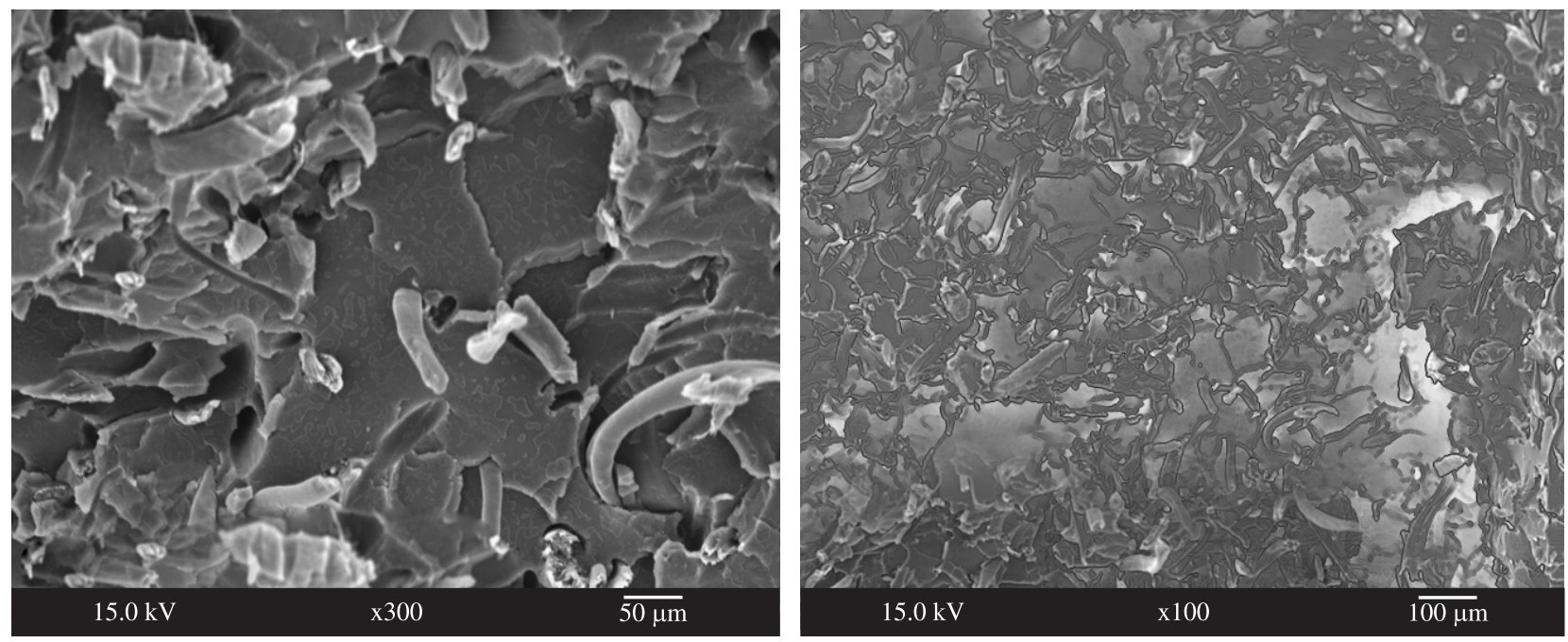

(b)

Figura 10. Microscopia de MEV dos compósitos com 10\% de fibra de algodão: a) sem agente compatibilizante, e b) com agente compatibilizante. 

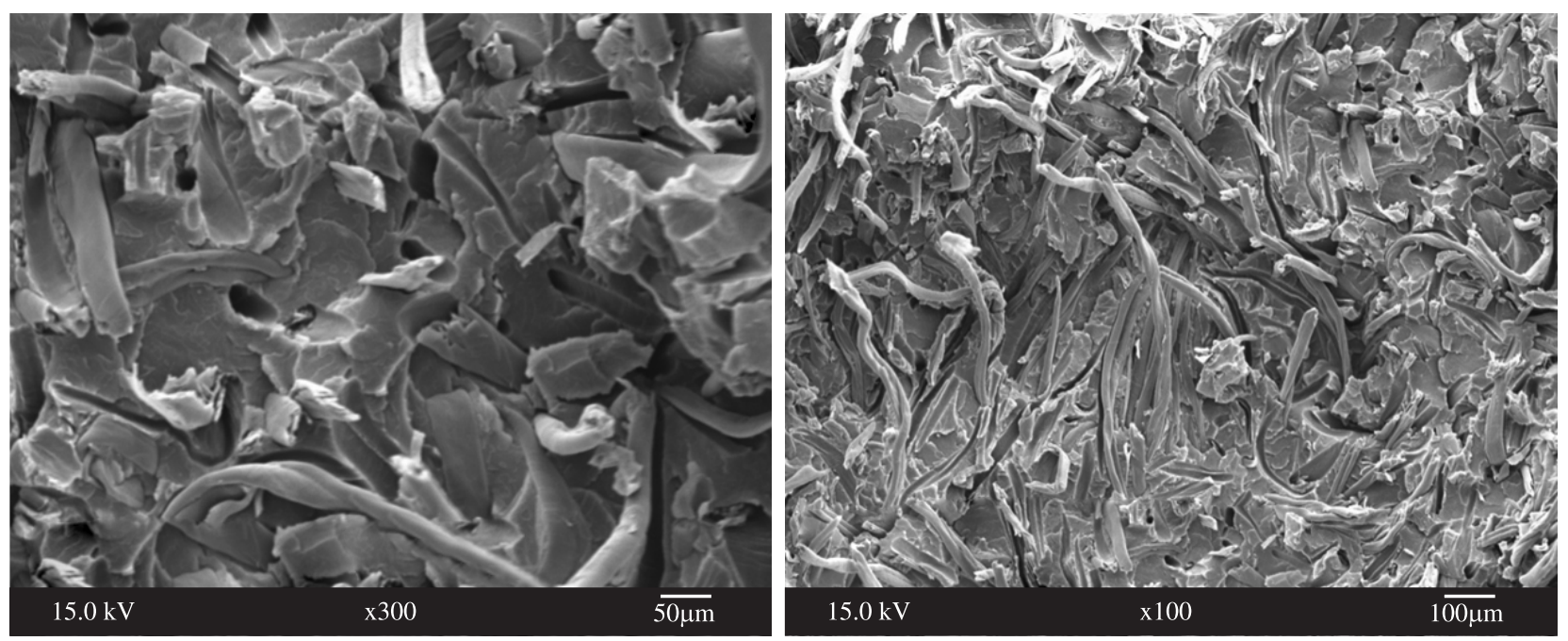

(a)
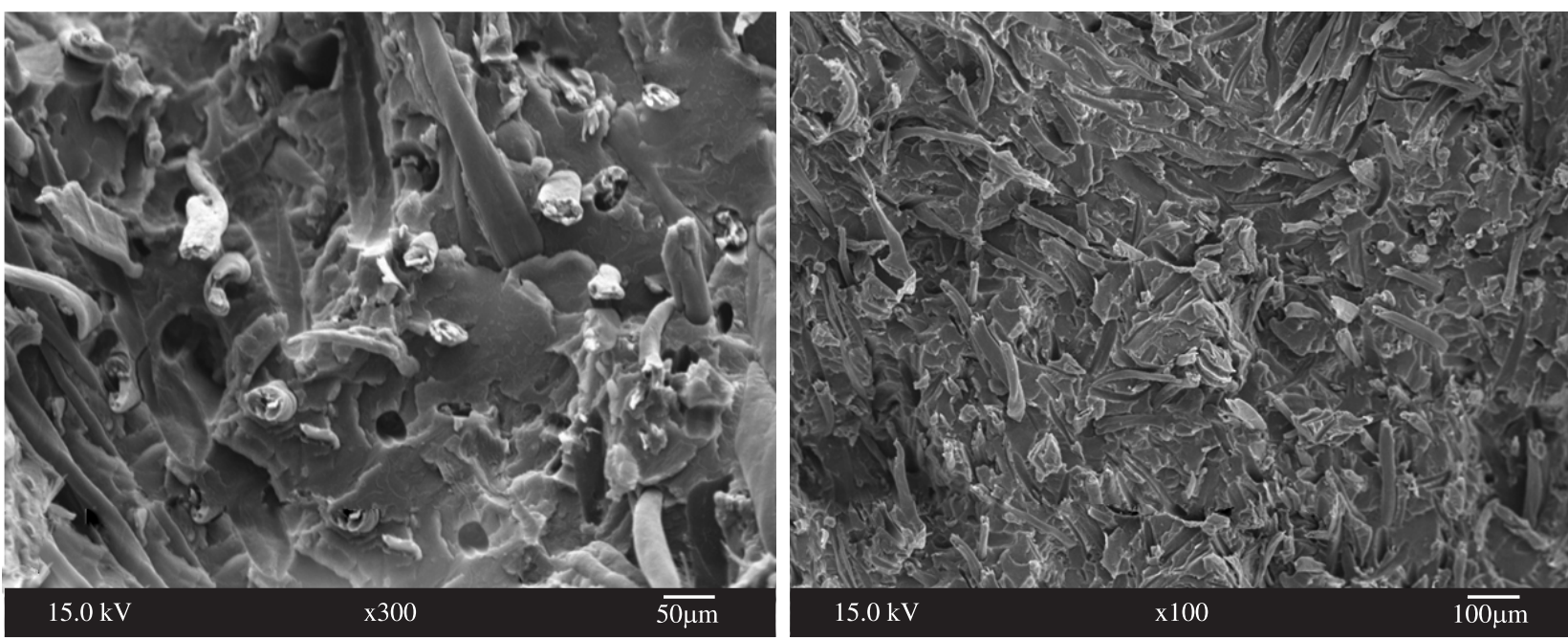

(b)

Figura 11. Microscopia de MEV dos compósitos com 20\% de fibra de algodão: a) sem agente compatibilizante, e b) com agente compatibilizante.

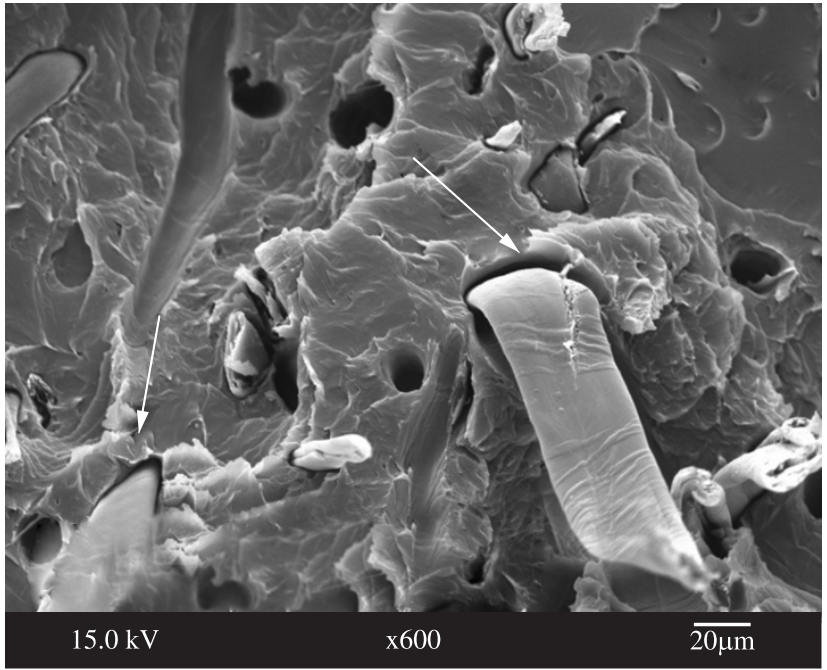

(a)

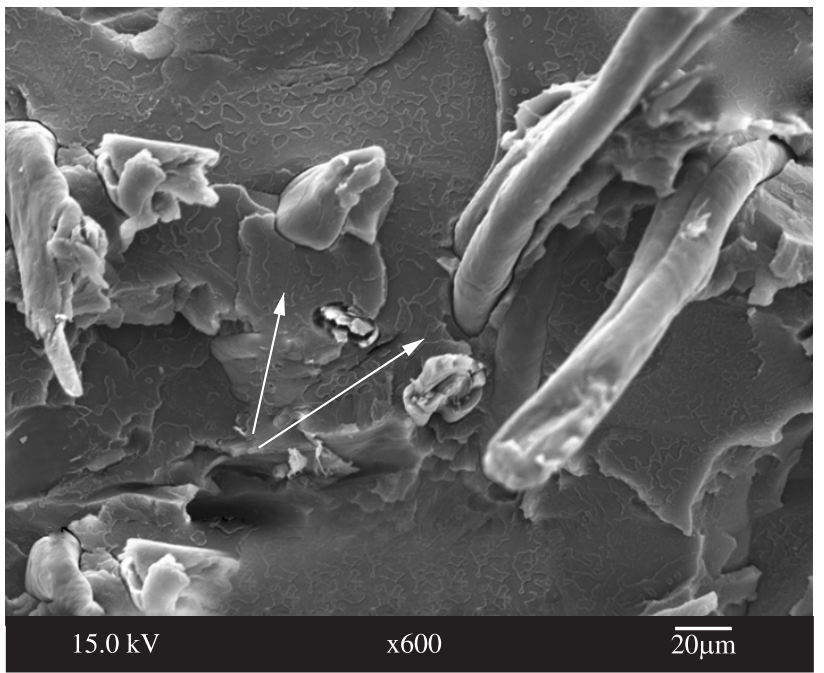

(b)

Figura 12. Microscopia de MEV dos compósitos com 10\% de fibra de algodão: a) sem agente compatibilizante, e b) com agente compatibilizante. 


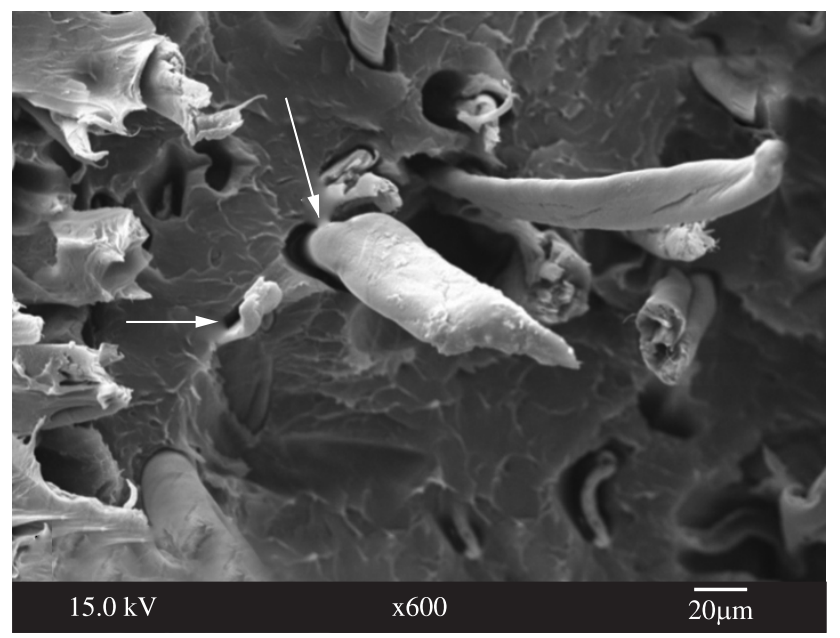

(a)

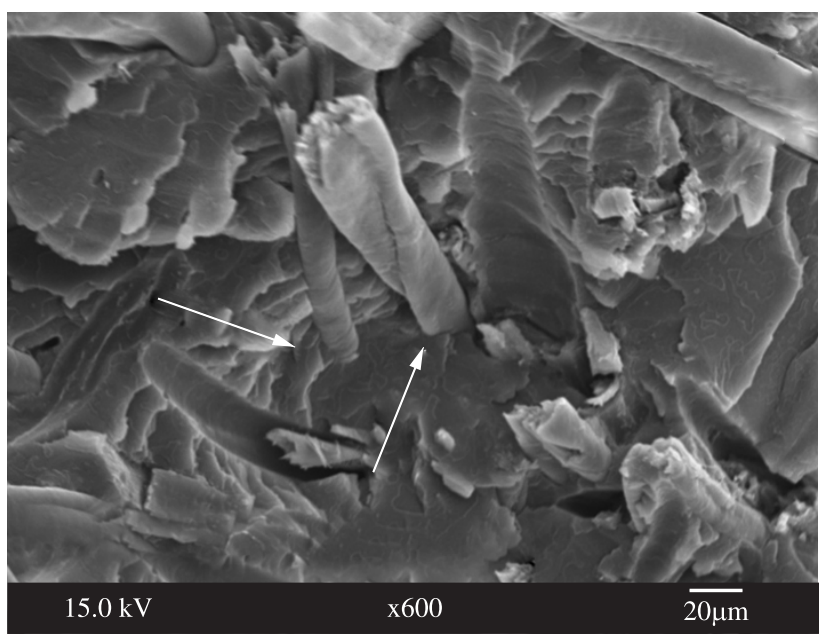

(b)

Figura 13. Microscopia de MEV dos compósitos com $20 \%$ de fibra de algodão: a) sem agente compatibilizante, e b) com agente compatibilizante.

desenvolvidos com polipropileno modificado com anidrido maleico. Por meio da microscopia, verificaram que o compatibilizante possibilita maior adesão interfacial entre a fibra celulósica e a matriz termoplástica, independentemente da granulometria da farinha de madeira utilizada.

\section{Conclusões}

Em relação ao ensaio de flexão, a adição de fibra de algodão faz com que a resistência à flexão aumente, sendo esse efeito mais pronunciado com a utilização do agente compatibilizante. Para a amostra com $10 \%$ de fibra com SMA 2000, observa-se uma diminuição da resistência à flexão, podendo estar associada à não uniformidade na distribuição das fibras.

O ensaio de tração demonstra que a adição de $20 \%$ de fibra de algodão ao PS aumenta a resistência à tração, indicando uma melhor transferência de esforços da matriz para a carga de reforço, ainda mais evidente quando utilizado agente compatibilizante. Isto também foi constatado em relação ao módulo de elasticidade para o percentual de $20 \%$ de fibra de algodão.

Pelos testes de impacto, observa-se que a adição das fibras de algodão aumenta a resistência ao impacto dos compósitos; porém, esse efeito é reduzido é quando utilizado agente compatibilizante. Acredita-se que esse comportamento seja devido à migração do agente compatibilizante para o interior da fibra, reduzindo a resistência ao impacto do compósito.

Os resultados de HDT demonstram que a presença da fibra de algodão produz um aumento no valor da temperatura de deflexão para todos os compósitos, sendo de $7{ }^{\circ} \mathrm{C}$ para os compósitos com $20 \%$ de fibra de algodão.

Mediante análise termogravimétrica, observou-se que a temperatura de degradação térmica dos compósitos PS/fibra de algodão diminuiu em relação ao PS, fazendo com que o processo de degradação térmica iniciasse em aproximadamente $200^{\circ} \mathrm{C}$.

Pela análise de DMTA, percebe-se que, com a adição das fibras de algodão, diminui o grau de amortecimento, como consequência da redução da fração da matriz, de maior ductilidade.

Em relação ao módulo de armazenamento, constata-se que este aumenta com a incorporação de fibras de algodão. Com a utilização de agente compatibilizante, tem-se uma melhor adesão na interface fibra/ matriz, esperando-se um acréscimo do módulo de armazenamento. Porém, um efeito contrário foi constatado para os compósitos com $10 \%$ de fibra. Esse comportamento ocorreu, provavelmente, devido a uma distribuição não uniforme das fibras no compósito.
Pelos ensaios de MEV, percebe-se que, para $10 \%$ de fibra de algodão, a distribuição não é homogênea, pois foram verificados muitos espaços sem fibras. A adição de $20 \%$ de fibra de algodão faz com a resistência à tração e à flexão aumente, como pode ser observado na microscopia, a distribuição das fibras é homogênea. Em relação à região de interface, observa-se uma melhora da adesão fibra/matriz, com a utilização do agente compatibilizante.

A incorporação de fibras de algodão, provenientes do processo de tecelagem em indústria têxtil, na matriz de poliestireno, torna-se uma alternativa para a reciclagem desses resíduos. Mediante estudos do presente trabalho, a incorporação de $20 \%$ de fibras de algodão se torna viável. Por consequência, a adição de $20 \%$ em massa de resíduos de fibras de algodão, que possui um custo zero, implica em uma economia de $20 \%$ de resina virgem de poliestireno. Além de gerar uma redução de consumo de resina virgem, o resíduos consumidos no processamento dos compósitos, não são dispostos em aterros, e dessa forma eliminando o custo de disposição em aterro. Assim, a utilização de resíduos da indústria têxtil, reduz o custo do material compósito produzido e gera um aumento nas suas propriedades mecânicas e térmicas.

\section{Referências Bibliográficas}

1. Araujo, J. R.; Mano, B.; Teixeira, G. M.; Spinacé, M. A. S. \& De Paoli, M. A. - Comp. Sci. Tech., 70, p.1637 (2010). http://dx.doi. org/10.1016/j.compscitech.2010.06.006

2. Santos, P. A.; Spinace, M. A. S.; Fermoselli, K. K. G. \& De Paoli, M. A. - Comp. Part A., 38, p.2404 (2007). http://dx.doi.org/10.1016/j. compositesa.2007.08.011

3. Corradini, E.; Ito, E. N.; Marconcini, J. M.; Rios, C. T.; Agnelli, J. A. M. \& Mattoso, L. H. C. - Polym. Test., 28, p.183 (2009). http://dx.doi. org/10.1016/j.polymertesting.2008.11.014

4. Manikandan Nair, K. C.; Diwan, Z. S. M. \& Thomas, S. - J. Appl. Polym. Sci., 60, p.1483 (1996).

5. Machado, M. L. C.; Pereira, N. C.; Miranda L. F. \& Terence M. C. - Polímeros, 20, p.65 (2010). http://dx.doi.org/10.1590/S010414282010005000011

6. Bourmaud, A. \& Baley, C. - Polym. Degr. Stab., 92, p.1034 (2007). http://dx.doi.org/10.1016/j.polymdegradstab.2007.02.018

7. Garcia, M.; Garmendia, I. \& Garcia, J. - J. Appl. Polym. Sci., 107, p.2994 (2008). http://dx.doi.org/10.1002/app.27519 
8. Bledzki, A. K. \& Gassan, J. - Progr. Polym. Sci., 24, p.221 (1999). http://dx.doi.org/10.1016/S0079-6700(98)00018-5

9. Sgriccia, N.; Hawley, M. C. \& Misra, M. - Comp. Part A., 39, p.1632 (2008). http://dx.doi.org/10.1016/j.compositesa.2008.07.007

10. Kim, S-J.; Moo, J-B.; Kim, G-H. \& Ha, C-S. - Polym. Tes., 27, p.801 (2008). http://dx.doi.org/10.1016/j.polymertesting.2008.06.002

11. Coutinho, F. M. B.;Costa, T. H. S. - Polym. Tes., 18, p.581 (1999). http://dx.doi.org/10.1016/S0142-9418(98)00056-7

12. Manikandan Nair, K. C.; Thomas, S. - Polym. Comp., 24, p.332 (2003).

13. Xue, Y.; Veazie, D. R.; Glinsey, C.; Horstemeyer, M. F. \& Rowell, R. M. - Comp. Part B., 38, p.152 (2007). http://dx.doi.org/10.1016/j. compositesb.2006.07.005

14. Pracella, M.; Chionna, D.; Anguillesi, I.; Kulinski, Z. \& Piorkowska, E. - Comp. Sci. Tech., 66, p.2218 (2006). http://dx.doi.org/10.1016/j. compscitech.2005.12.006

15. Pita, P. - "Fibras têxteis", SENAI - CETIQT, Rio de Janeiro (1996).

16. Poletto, M. - "Obtenção e caracterização de compósitos preparados com poliestireno expandido e pó de madeira", Dissertação de Mestrado, Universidade de Caxias do Sul, Brasil (2009).
17. Mwaikambo, L. Y. \& Bisanda, E. T. N. - Polym. Tes., 18, p.181 (1999). http://dx.doi.org/10.1016/S0142-9418(98)00017-8

18. Antich, P.; Vazquez, A.; Mondragon, I. \& Bernal, C. - Comp. Part A., 37, p.139 (2006). http://dx.doi.org/10.1016/j.compositesa.2004.12.002

19. Araujo, J. R.; Waldman, W. R. \& De Paoli, M. A. - Polym. Degr. Stab., 93, p.1770 (2008). http://dx.doi.org/10.1016/j. polymdegradstab.2008.07.021

20. Hameed, N.; Sreekumar, P. A.; Francis, B.; Yang, W. \& Thomas, S. - Comp. Part A., 38, p.2422 (2007). http://dx.doi.org/10.1016/j. compositesa.2007.08.009

21. Mohanty, S.; Verma, S. K. \& Nayak, S. K. - Comp. Sci. Tech., 66, p.538 (2006). http://dx.doi.org/10.1016/j.compscitech.2005.06.014

22. Correa, C. A.; Fonseca, C. N. P.; Neves, S.; Razzino, C. A. \& Hage, E. - Polímeros, 13, p.154 (2003). http://dx.doi.org/10.1590/S010414282003000300005

Enviado: $27 / 09 / 10$

Reenviado: 21/11/10

Aceito: 08/01/2011

DOI: $10.1590 / \mathrm{S} 0104-14282011005000055$ 